\title{
Influencing factor and cost optimization of ferrous charges consumption for converters
}

\author{
Yu Tang \\ CISDI Engineering Co., Ltd. \\ Chongqing, 401122, China \\ E-mail:Yu.A.Tang@cisdi.com.cn
}

\begin{abstract}
In order to control the production cost of the converters, the production data investigation was done on site at one steelmaking plant. The investigation is mainly about the ferrous charges consumption. It is seen that the ferrous charges consumption in this plant is at the middle level among several Chinese plants in the analytical scope. The influencing factors of the ferrous charges consumption are analyzed in order to reduce the ferrous charges consumption. It is shown that $[\mathrm{Si}]$ content in hot metal, oxygen blowing duration, tapping temperature, T. Fe content in the slag, etc have influence on the ferrous charges consumption.
\end{abstract}

Keywords: Ferrous Charges Consumption; Hot Metal; Scrap.

\section{Introduction}

Chinese iron and steel industry has entered the era of meagre benefit and adjusting period. Under this circumstance, the steelmaking enterprise with lower cost and higher efficiency will survive or become winner.

In order to control the production cost, among many aspects, the raw material is a key factor. For converters, the most important raw material is the ferrous charges including hot metal, scrap, pig iron, etc. If the ferrous charges consumption can be reduced, there will be huge benefit.

At present, according to some statistics about the ferrous charges consumption[1 9], the ferrous charges consumption in this plant is at the middle level. So there is still some potential to be exploited for the reduction. The first step is to find out the influencing factors of ferrous charges consumption.

It is shown by previous papers that hot metal compositions, charges components, oxidizing property of slag and steel grades would influence the ferrous charges consumption. By increasing iron ore and self-made iron balls, the ferrous charges consumption would be reduced. In addition, it can also be reduced by improving the slag making process and reducing oxygen blowing intensity[1 3]. 
By investigating and analyzing the realistic production data, we find out the reason why the ferrous charges consumption in this plant is higher than the advanced level in other plants in China. And on the basis of this, some production suggestions for reducing the consumption level are given.

\section{Investigation and Results}

\subsection{Investigation}

The site investigation was done at one steelmaking plant in Southern China. It has two sets of $200 \mathrm{t}$ top and bottom combined blown converters, whose annual capacity is 4.5 million ton per year.

All production data of the converters for 1.5 years were investigated and analyzed systematically. In this paper, we mainly talk about the ferrous charges consumption.

\subsection{Results}

The consumption (including hot metal, scrap, pig iron) per ton steel is shown as Table 1. It is shown by Table 1 that the ferrous charges (sum of the three items) is $1064 \mathrm{~kg} / \mathrm{t}$.

Table 1. Hot metal, scrap and pig iron consumption per ton steel.

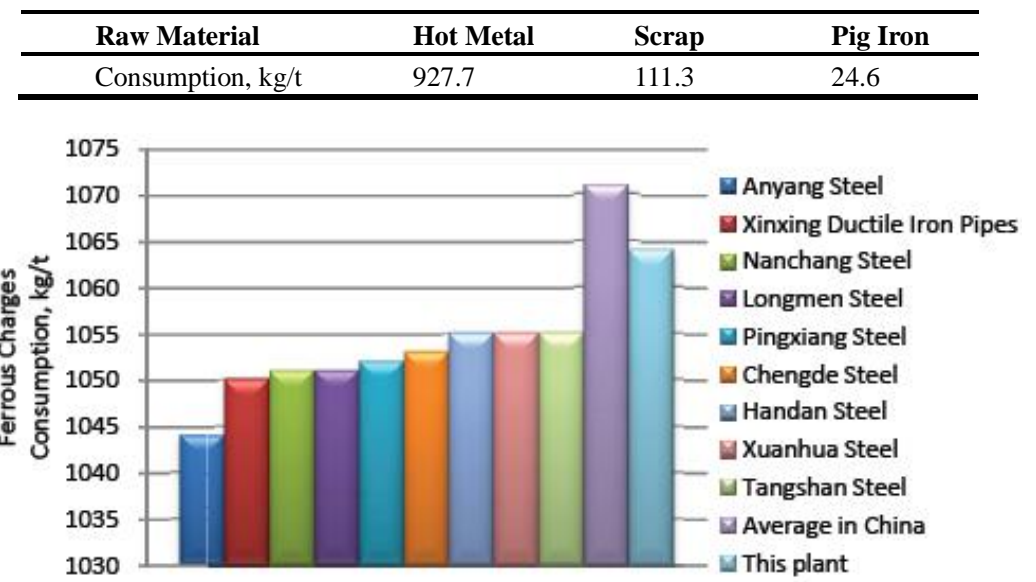

Fig. 1. The comparison of ferrous charges consumption between some steelmaking plants in China

Figure 1 shows the comparison of the ferrous charges consumption between some steelmaking plants in China. It is shown that the consumption in this plant is $7 \mathrm{~kg} / \mathrm{t}$ lower that China average level $1071 \mathrm{~kg} / \mathrm{t}$, but $20 \mathrm{~kg} / \mathrm{t}$ higher than the 
lowest one $(1044 \mathrm{~kg} / \mathrm{t})$. Besides the lowest one, there are still many other plants lower than this plant. So there is still improving space for this plant.

\section{Discussion}

Now, let's investigate the influencing factors of the ferrous charges consumption and the reason why it is higher than some plants.

\section{1. [Si] Content in Hot Metal}

If [Si] content in hot metal is higher, the slag quantity would be higher, leading to higher metal loss.

Figure 2 shows the rate distribution of different [ $\mathrm{Si}$ ] content in charging hot metal. It is shown that the rate of $0.31 \sim 0.40 \%, 0.41 \sim 0.50 \%$ and $>0.51 \%$ [Si] is $42.28 \%, 35.22 \%$ and $13.90 \%$ respectively. So, it can be seen that the rate $>0.4 \%$ [Si] is $49.12 \%$, leading to higher slag quantity and higher ferrous charges consumption.

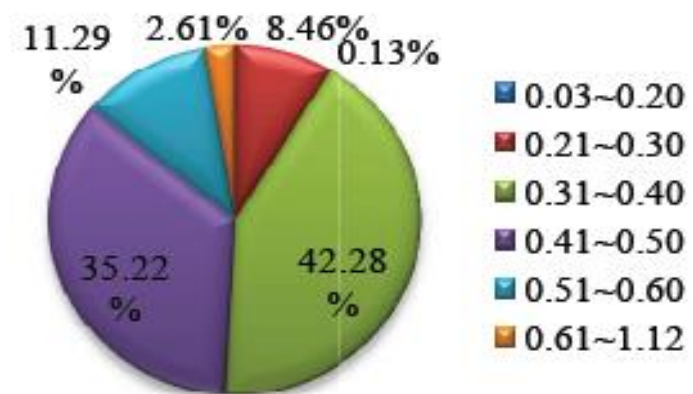

Fig. 2. Rate distribution of different $[\mathrm{Si}]$ content (\%) in charging hot metal

\subsection{Oxygen blowing duration}

If oxygen blowing duration is longer, the burnt metal will be more.

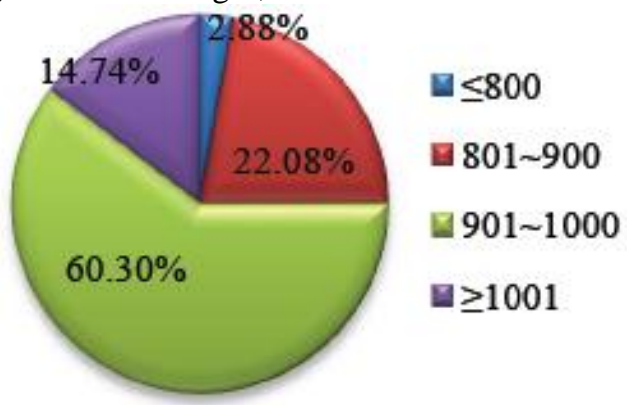

Fig. 3. Rate distribution of different oxygen blowing duration (s) 
Figure 3 shows the rate distribution of different oxygen blowing duration. It is shown that the rate $>900 \mathrm{~s}$ is $75.04 \%$, which is a longer time than normal level, leading to more burnt metal and accordingly higher ferrous charges consumption.

\subsection{Tapping temperature}

If the tapping temperature is higher, the evaporated Fe will be higher and enter into the off-gas, meanwhile leading to more air sucking-in, not beneficial for the molten steel quality.

The rate distribution of different tapping temperature is shown by Figure 4 . It is shown that the rate of tapping temperature $>1630^{\circ} \mathrm{C}$ is $58.83 \%$, among which $>1660^{\circ} \mathrm{C}$ is $33.09 \%$. It can be seen that the tapping temperature is higher than normal level. For Tangshan Steel, its tapping temperature was reduced to $1631.89^{\circ} \mathrm{C}$ in 2006 [8]. So there is improving space for the tapping temperature in this plant.

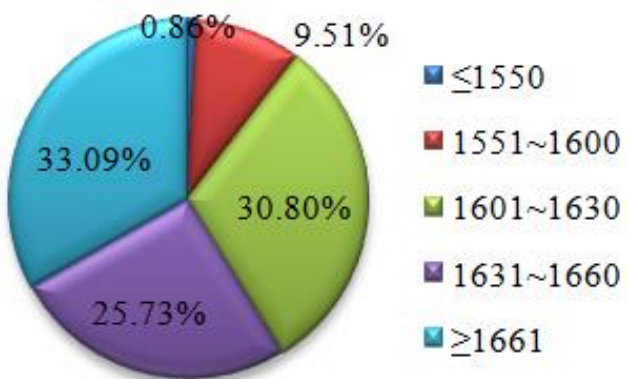

Fig. 4. Rate distribution of different tapping temperature $\left({ }^{\circ} \mathrm{C}\right)$.

\subsection{Oxidizing property of the slag}

If the oxidizing property or $\mathrm{T}$. Fe content in the slag after converter tapping is higher, the metal loss will be higher, leading to the increase of ferrous charges consumption.

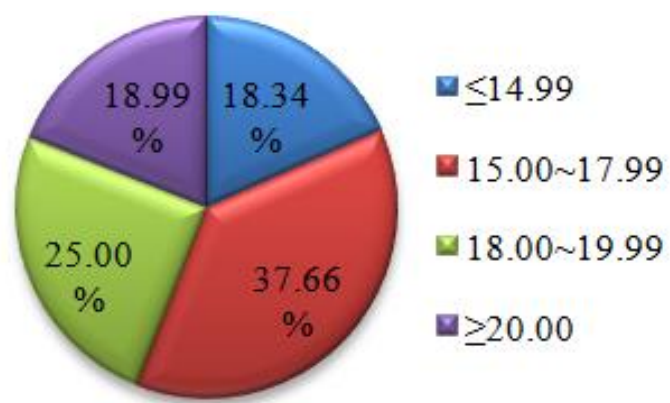

Fig. 5. Rate distribution of different T. Fe content in the slag after converter tapping (\%). 
Figure 5 shows the rate distribution of different T. Fe content in the slag after converter tapping. It is shown that the rate $>18 \% \mathrm{~T}$. Fe is $43.99 \%$, among which it is $18.99 \%$ when T. Fe $>20 \%$. So it can be seen that T. Fe content in the slag is higher than normal level.

Figure 6 shows the comparison of T. Fe between several Chinese steelmaking plants. It is shown that for this plant, it is higher than $16.88 \%$ (Tangshan steel) and 16.5\% (Handan steel), still possible to be reduced further.

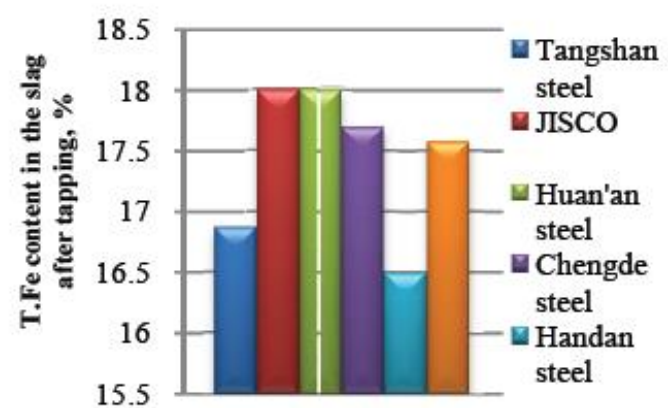

Fig. 6. Comparison of T. Fe between several Chinese steelmaking plants.

\subsection{Slag quantity}

If the slag quantity is higher, accordingly, the metal included in the slag will be also higher. The slag quantity for this plant is $120 \sim 130 \mathrm{~kg} / \mathrm{t}$.

Figure 7 shows the comparison of slag quantity between several Chinese steelmaking plants. It is shown that the slag quantity for this plant is $39.58 \mathrm{~kg} / \mathrm{t}$ higher than JISCO, still possible to be reduced further.

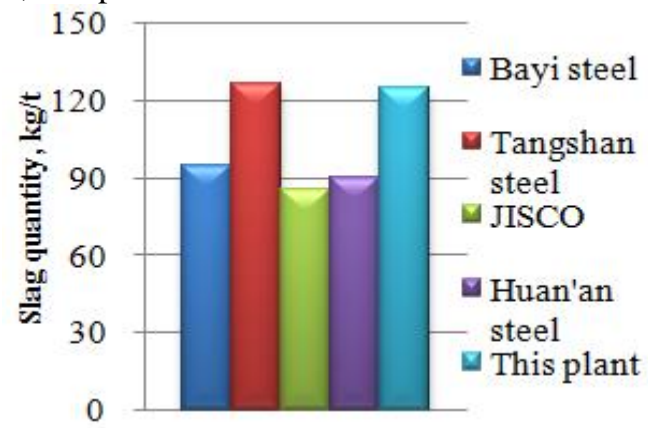

Fig. 7. Comparison of slag quantity between several Chinese steelmaking plants.

\subsection{Other factors}

(1)Reblowing rate

This plant is equipped with sublance. However, the reblowing rate is $10 \%$, higher than the normal level. On the other hand, under the circumstance without 
sublance, the reblowing rate for Sanming steel was $6.76 \%$ in $2009^{[10]}$. So it can be seen that for this plant, the reblowing rate is reasonable to be reduced further.

(2)Bottom blowing

On site investigation shows that the effect of converter bottom blowing is not very perfect, which is one of the reasons for the high oxidizing property of slag and high reblowing rate.

(3) Spitting

On site investigation shows that there are spitting or slopping accident occasionally, leading to metal loss.

\section{Conclusions}

Based on above, conclusions can be drawn that [Si] content in hot metal, Oxygen blowing duration, Tapping temperature, Oxidizing property of the slag, slag quantity, reblowing rate, bottom blowing, spitting would influence the ferrous charges consumption.

In order to reduce the ferrous charges consumption to keep the competitiveness of this plant, some measurement can be done without changing the components of the ferrous charge, such as:

(1)To control [Si] content in hot metal by hot metal pretreatment and keep it as stable as possible;

(2)To optimize oxygen blowing practice to keep the blowing duration within reasonable range;

(3)To lower tapping temperature and $\mathrm{T}$. Fe content in the slag after converter tapping;

(4)To improve sublance practice to make sure of high hit rate, reducing reblowing rate;

(5)Slide gate slag stopper can be used to increase metal yield;

(6)To improve the production practice to reduce spitting or slopping accident;

By the measurements above, it is estimated that the ferrous charges consumption can be reduced $4 \sim 6 \mathrm{~kg} / \mathrm{t}$ at least. That is to say, the production cost can be reduced about 10 12 RMB/t steel. For one steelmaking plant with 4.5 million ton capacity per year, if all the measurement can be executed, there will be 45 54 million RMB saved every year.

\section{References}

1. Zhang Changping, et al. Calculation and Analysis of Steel Charging Material Consumption in the NO. 1 Working Procedure of JISCO. Gansu Metallurgy, 2008, 30 (3): 8-11 
2. Wang Zhaohong, et al. Analysis and Discussion of Factor Influencing Converter Charge Consumption. Metal World, 2007, (4): 53-55

3. Wu Jianwei. Research and Practice on Optimizing Charge Structure in 100t Combined Blowing Converters. The China Iron and steel annual conference proceedings, 2011

4. Feasibility Research of the Measure on Decreasing the Ferrous Charges Consumption on Converter. The China Iron and steel annual conference proceedings, 2007

5. Liu Yuwei, et al. The Analysis Practice in Reducing Ferro Metal Consumption. The $14^{\text {th }}$ China Steelmaking academic conference proceedings, 2006: 240-243

6. Li Shuangwu, et al. Practice to Reduce Consumption of Iron and Steel Material. Hebei Metallurgy, 2011, (1): 28-31

7. Hou Cheng. Research and Control of Raw Metals Consumption in BOF Plant. The $11^{\text {th }}$ China Steelmaking academic conference proceedings, 2000: 27-35

8. Sun Jianyong, et al. Practice of Reducing the Tapping Temperature in Tang steel. Industrial Heating, 2010, 39 (1): 50-53

9. Liu Haichun, et al. Process Practice on Rifining Results of 100t Combined Blown Converter. IRON AND STEEL, 2006, 41 (2): 200-202

10. Huang Biaocai, et al. Application of the auto-steelmaking technology without sublance or gas analysis system in 100t converter. China steelmaking and continuous casting production technology conference proceedings, 2010: 235-240 